\title{
The Correlation of Spatial Distribution Between Surface Deformation and Landslides by SBAS-InSAR and Spatial Analysis in Longnan Region, China
}

\author{
Xue Yating, Meng Xingmin", Guo Peng, Li Kai and Chen Guan \\ Key Laboratory of West China's Environmental Systems, Lanzhou University, Gansu, China
}

\begin{abstract}
We use interferometric synthetic aperture radar (InSAR) time-series analysis of Envisat ASAR data to reveal the correlation of distribution between surface deformation and landslides in western China. The results of SBAS-InSAR revealed that the velocity of surface deformation is between $-18.6 \mathrm{~mm} /$ year to $26.8 \mathrm{~mm} /$ year. The landslides data which we extracted from SPOT 5 image and investigated in field were correlated with altitude, lithology, slope, degree, land-use, fault, NDVI and distance to river. We found that the landslides mainly distribute on $13^{\circ} \sim 41^{\circ}$ slope degree, $1200 \mathrm{~m} \sim 2000 \mathrm{~m}$ altitude, the strong human activity, the poor vegetation covered, near the river and fault, underlain medium thickness limestone and thin-layered siltstone and mud stone. Using the landslides distribution features, landslides will be identified from the results of surface deformation and landslides susceptibility will be assessed. This method can help local government rapidly monitor landslides and assess landslides susceptibility on large scale.
\end{abstract}

Keywords: SBAS-InSAR, landslides, surface deformation, spatial analysis.

\section{INTRODUCTION}

Longnan, the weak rock area, is one of the four areas in China most severely affected by landslides and debris flow events. Since 1975, there are 76 persons who lost their lives in landslides hazard [1], whereas the property damage is too much to count. To protect human life and property, assessing the landslides susceptibility is an essential task in this region.

In recent years, some research have been applied by field investigation or geostatistics method (such as ANN, AHP) to assess the landslides susceptibility in this region $[2,3]$. And they often used old data such as lithology, land-use to build assessment model. These old data have not been not updated since their first generation. The mathematical model is difficult to simulate the complex landslide activity. In order to obtain the valuable data for landslides investigation on large scale and avoid the limitations of geostatistics method, Synthetic Aperture Radar interferometry (InSAR) is applied in this study to detect surface deformation which may monitor the activity of landslides.

The use of InSAR for surface deformation mapping has been demonstrated in many applications, such as monitoring the land subsidence $[4,5]$, the correlation of distribution between land subsidence and urbanization [6], geoenvironmental hazards [7], earthquake [8] and landslide assessment [9]. InSAR technology can provide reliable measurement results $[10,11]$, indicating surface deformation. According to the distribution of surface deformation, landslides or potential landslide may be detected, which is useful for mapping the landslides susceptibility on the

*Address correspondence to this author at Key Laboratory of West China's Environmental Systems, Lanzhou University, Gansu, China, 730030, P.R. China; Tel: +86 13659478056; E-mail: xmmeng@1zu.edu.cn regional scale [12], which the local government can use to select safe zone for slope engineering management and landscape planning. However, only the results obtained from InSAR are not reliable for measuring the landslides susceptibility. We also need a statistic method to reveal the correlation of distribution between surface deformation and landslides.

The InSAR assessment model is limited by mathematical method, snce this is not a precise model. In 2014, Xu adopts spatial analysis method to study the distribution of landslides [13]. It is different from traditional geostatistics method. This method directly reveals the characteristic of landslides distribution in different landslides impact factors. It is innovative for us to study the characteristics of landslides distribution. For which, we can first use this method to study the surface deformation distribution to reveal the characteristic of distribution.

In this study, considering that this area is well vegetated, we applied the SAR interferometry algorithm referred to as Small Baseline Subset (SBAS) approach [14] that allowed us to generate mean deformation velocity maps and displacement time series for the investigated area. Then, we used previous landslides map to analyze the characteristic of landslides spatial distribution in the study area. Meanwhile, the precision new data, generating from SBAS-InSAR, also be processed to analyze the characteristic of surface deformation spatial distribution. The two characteristics were compared with each other to find the correlation of distribution between them. After obtaining the correlation of distribution between landslides and surface deformation, we could easily select the areas which are landslides area or potential landslides area. The characteristics study of existing landslides can help us to build landslides distribution model. As is well known, not all the surface 
deformation are essentially the landslides. Therefore, we used the results of existing landslides spatial distribution model to deduce surface deformation areas which are potential landslides regions. This method can be used to detected landslides and analyze slope susceptibility on the regional scale only by using InSAR technology. It is different from the previous methods used to assess landslides susceptibility. Besides, it can be applied to any region to analyze landslides susceptibility.

\section{STUDY AREA}

Longnan is located at southern part of Gansu, China (Fig. 1). It belongs to Bailong River basin. The Bailong river catchment covers an area of $185000 \mathrm{~km}^{2}$ in southern Gansu as the secondary tributary of the Yangtze River. The study area we selected included the main city of the region Wudu. The city is seriously affected by landslides.

In this region, the average temperature is $12.9^{\circ} \mathrm{C}$. The average annual rainfall in the study area is $447.0 \mathrm{~mm}$. The 80 percent of rainfall occurs in the period from June to September and frequent, heavy rainstorms in summer.

The topography in this region is rugged and it has a diacritic drainage pattern. As the neo-tectonic deformation (thrusts, faults and fold-belts), the complex geology and river erosion control slope gradients. In this region, outcrops include phyllites, limestones, metamorphic sedimentary rocks, shales, schists, slates and sandstones of the Silurian, Devonian and Carboniferous periods, clastic rocks and mudstones of the Jurassic, Carboniferous and Neogene periods. Quaternary materials include mainly loess, colluvium and alluvium.

As the region is located at the conjunction between multiple structural units involving overlapping of the Qinling and Songpan-Ganzi fold belts and the Wudu epsilon-shaped structure, tectonic activity is very strong in this region. There are several large earthquakes happened in the past time. Only $\mathrm{M}_{\mathrm{S}}=8.0$ earthquake happened twice. One is the Tianshui earthquake happened in 1654, another is the Wudu earthquake happened in 1879 . The 2008 "5.12" Wenchuan earthquake also affected this region by triggering many landslides and weakened slopes.

\section{DATA AND METHOD}

\subsection{Data}

Our research is based on a total of 32 Envisat ASAR scenes spanning from August 2003 to Semptember 2010. The image acquired on May 28, 2008 was selected as the master image. Here, we used GDEM (30m resolution) and Envisat satellite precision orbit data from Delft University of Technology for detecting surface deformation. In this research study, we used the software StaMPS/MTI [15] to identify PS pixels and extract deformation signatures.

In order to analyse the cause of surface deformation, we used GDEM to generate slope map and altitude map. Remote sensing images are the foundation of a comprehensive inventory of landslides because landslides always distribute in a broad area which cannot be fully accessed during field investigations. The landslides inventory map is based on SPOT 5 images taken on March 24, 2009, combined with extensive field surveys from 2010 to 2012. In study field, the total number of landslides are 105. Distance from faults is the Euclidean distance from the faults (most of them are active) based on digitizing the 1:200,000 scale of geological map. The lithology is also generated from 1:200,000 geological map and divided into seven categories according to composition, physical-mechanical characteristics and sensitivity to sloping. The categories of lithology include: (A): metasandstone, metamorphic conglomerate; (B): phyllite, slate; (C): medium thickness limestone; (D): slate with limestone and gravel; (E): thin-layered siltstone, mudstone; (F): sand and gravel layer; and (G): loess, clay. Then, we used 3 TM images on 2000 to obtain landuse data and NDVI data. Using ArcGIS, we calculated the distance to river.



Fig. (1). The map of study area, in Longnan, China. 
Table 1. Classifications of impact factors.

\begin{tabular}{|c|c|c|c|}
\hline No. & Impact factor & Types number & Classification \\
\hline \hline 1 & Slope & 5 & $0 \sim 13^{\circ} ; 13^{\circ} \sim 27^{\circ} ; 27^{\circ} \sim 41^{\circ} ; 41^{\circ} \sim 54^{\circ} ; 54^{\circ} \sim 67.7^{\circ}$ \\
\hline 2 & Distance to fault(m) & 3 & $0 \sim 2.9 \times 10^{6} ; 2.9 \times 10^{6} \sim 6.9 \times 10^{6} ; 6.9 \times 10^{6} \sim 12.8 \times 10^{6}$ \\
\hline 3 & Altitude $(\mathrm{m})$ & 4 & $835 \sim 1200 ; 1200 \sim 2000 ; 2000 \sim 3000 ;>3000$ \\
\hline 4 & Lithology & 7 & A; B; C; D; E; F; G \\
\hline 5 & Land use & 6 & Grass; Settled area; Farmland; Forest; River; Unused area \\
\hline 6 & NDVI & 5 & A: $0.5 \sim 1 ;$ B: $0 \sim 0.5 ;$ C: $-0.4 \sim 0 ;$ D: $-0.7 \sim-0.4 ;$ E: $-1 \sim-0.7$ \\
\hline 7 & Distance to river(m) & 5 & $0 \sim 9 ; 9 \sim 26 ; 26 \sim 58 ; 58 \sim 118 ; 118 \sim 230.9$ \\
\hline
\end{tabular}

The impact factors can impact surface deformation or landslides. They are classified based on different classifications in order to find out the correlation of distribution between surface deformation and landslides. Table 1 shows the classifications of impact factors.

\subsection{Method}

In this paper, methods used include: SBAS-InSAR processing and spatial analysis with ArcGIS.

\subsubsection{SBAS-InSAR}

SBAS-InSAR method is an improved InSAR processing method compared with the previous methods. The previous methods such as PS-InSAR needed more SAR images and generatedthe long time series results. The longer the time series is, the more the temporal and spatial decorrelation exist. In this field, we adopted an advanced approach i.e. SBAS-InSAR. SBAS-InSAR uses interferograms with small baselines that overlap in order to reduce spatial decorrelation and to mitigate atmospheric artifacts and topographic errors in time-sequential interferometric pairs.
For using this algorithm, more pixels are exploited. Our study area is well vegetated. SBAS-InSAR can improve PS points number at well vegetated and non-urban areas.

StaMPS/MTI software is applied to generate surface deformation results based on SBAS algorithm in this research.

\subsubsection{Spatial Analysis Method}

In our work, we aim to reveal the correlation of distribution of distribution between surface deformation and landslides by spatial analysis. Based on impact factors such as slope, altitude, lithology and distance to fault, distance to river, land-use, NDVI, we count the density of surface deformation and landslides in different classification (Table $\mathbf{1}$ ). Then, the distribution trend between surface deformation and landslides will be compared. If the distribution trend is almost consistent, it shows the impact factor that has the same influence on surface deformation and landslides. If the distribution trend is obviously different, it indicates that the distribution of surface deformation and landslides have different impacts. The further research focuses on the cause of the difference creating different classifications with the

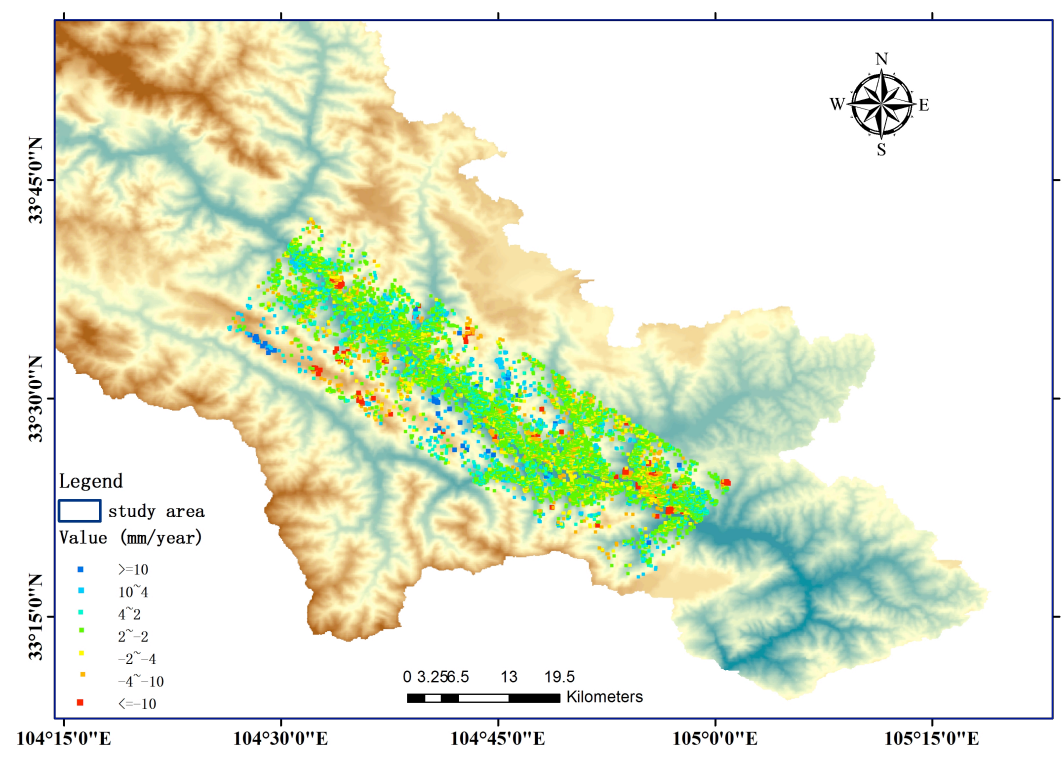

Fig. (2). The results of SBAS-InSAR. 
same impact factors. It can easily reveal which landslides fall in which classifications. Based these factors, we can build a model of landslides distribution. Then, we use the results of existing landslides spatial distribution model to deduce surface deformation areas which are potential landslides region. This method can be used to detect landslides and analyze slope susceptibility on regional scale only by InSAR technology.

\section{RESULTS}

\subsection{Results of SBAS-InSAR}

Fig. (2) shows the results of SBAS-InSAR. Obviously, the PS points we detected mainly distribute along the Bailong River. It depends on the high mountain and $\mathrm{V}$ shaped valley land-form in this region. A large quantity of rock lies at river bank. The rock is a good object for SBAS to detect as PS points.

In this research area, we identified 17833 PS points, the spatial coverage of which is $19.1 \mathrm{PS} / \mathrm{km}^{2}$, which is more than

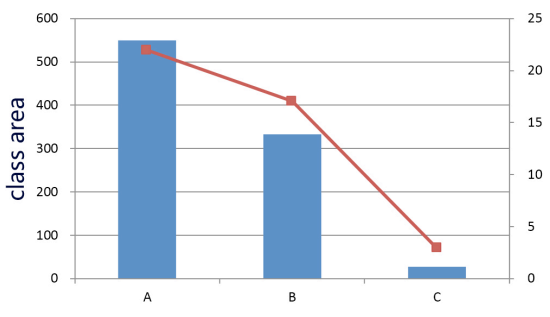

fault


the standard spatial coverage that is 3-4 PS/ $\mathrm{km}^{2}$. The deformation velocity in this area is found to be ranging between $-18.6 \mathrm{~mm} /$ year and $26.8 \mathrm{~mm} /$ year. Positive LOS velocities represent movement toward the satellite; negative LOS velocities represent movement away from the satellite.

\subsection{Correlation Between Surface Deformation and Impact Factors}

Correlations between the surface deformation density, area, topographics and geologics were analyzed. Seven surface deformation impact factors have been selected and assessed, consisting of the altitude, slope, lithology, distance to fault, distance to river, land use and NDVI.

Fig. (3) shows the relationship of the land area occupied by this class (class area) and surface deformation density in all classes of the seven factors. As is shown in Fig. (3) (altitude), when the absolute elevation increases, the density of surface deformation decreases down. Large density of surface deformation is occurred in the range of
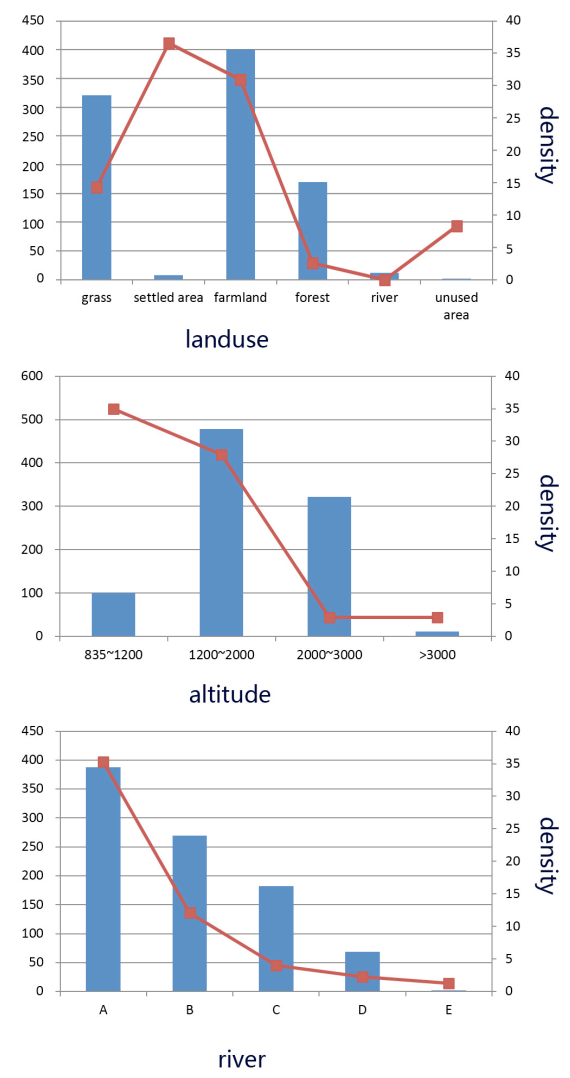

然

Fig. (3). The density of surface deformation under different impact factors. 
$835 \mathrm{~m} \sim 1200 \mathrm{~m}$, which is $34.9 \mathrm{~km}^{-2}$. Correlations between slope degree and surface deformation are shown in Fig. (3) (slope degree). The largest surface deformation density occurs in the range of $27^{\circ} \sim 41^{\circ}$, with surface deformation density of $20.5 \mathrm{~km}^{-2}$. Fig. (3) (lithology) shows the statistical result of the relationship between surface deformation density and lithology. The areas underlain by thin-layered siltstone and mudstone have the greatest susceptibility to surface deformation. The surface deformation density of this class is $35.2 \mathrm{~km}^{-2}$. Fig. (3) (distance to fault) shows the relationship between surface deformation density and distance to fault. When the distance becomes longer, the density will become lower. The largest range of distance to fault is $0 \sim 2.9 \times 10^{6} \mathrm{~m}$, which is $21.9 \mathrm{~km}^{-2}$. Distance to river is similar to distance to fault, as shown in Fig. (3). Surface


Fig. (4). The density of landslides under different impact factors. deformation easily occurs near the river. The largest density of surface deformation occurred in the range of $0 \sim 9 \mathrm{~m}$ with surface deformation density of $35.3 \mathrm{~km}^{-2}$. Fig. (3) (land-use) shows the correlations between land-use and surface deformation. Settled area is in the largest range where surface deformation occurred. The second largest range of land-use is farmland. Settled area and farmland indicate that the human activities strongly control surface deformation occurrance. Fig. (3) (NDVI) shows that the NDVI ranges of $0 \sim 0.5$ and $-0.4 \sim 0$ have the largest surface deformation density which are $40.99 \mathrm{~km}^{-2}$ and $40.13 \mathrm{~km}^{-2}$ respectively. The NDVI is a parameter that is used to determine vegetative cover. The bigger the value, the more the vegetative covered.
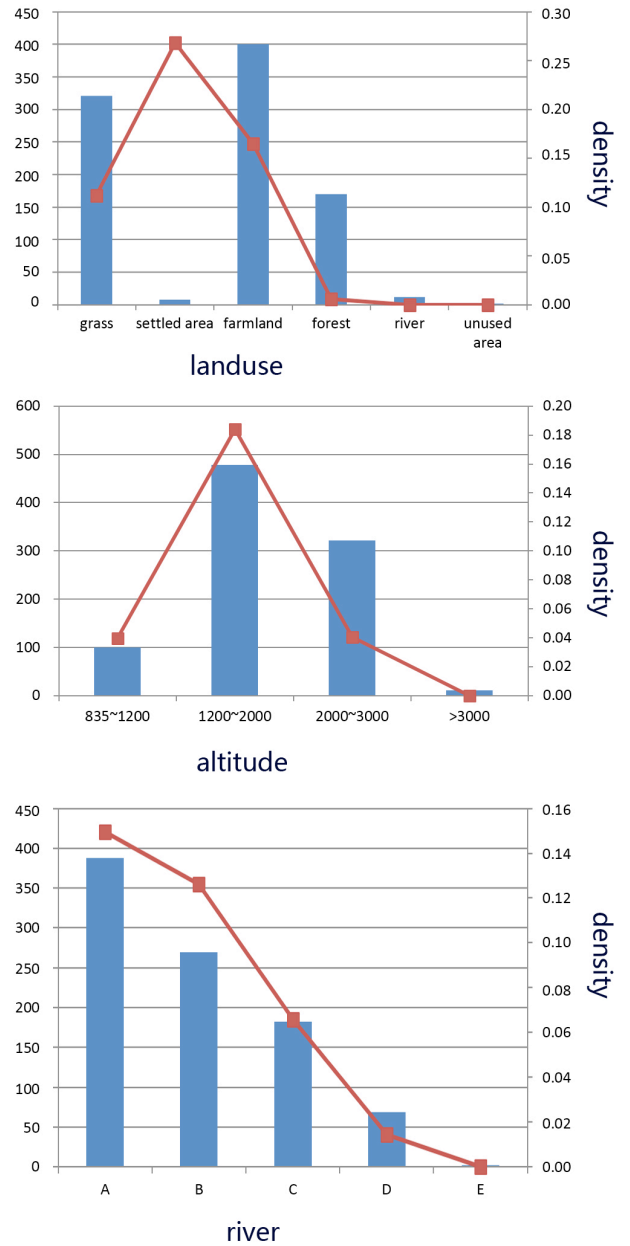

定

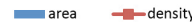

\section{$\stackrel{\stackrel{D}{D}}{\stackrel{P}{\vec{v}}}$}




\subsection{Correlation Between Landslides and Impact Factors}

Correlations between the landslides density, area, topographics and geologics were analyzed in this section. To analyze the correlation of distribution between surface deformation and impact factors, seven impact factors were selected and assessed, consisting of the altitude, slope, lithology, distance to fault, distance to river, land use and NDVI.

Fig. (4) shows the relationship of land area occupied by this class (class area) and landslides density in all classes of the seven factors. As is shown in Fig. (4) (altitude), large density of surface deformation occurred in the range of $1200 \mathrm{~m} \sim 2000 \mathrm{~m}$, which is $0.18 \mathrm{~km}^{-2}$. Correlations between slope degree and landslides are shown in Fig. (4) (slope degree). The largest landslides density occur in the range of $13 \sim 27^{\circ}$, with surface deformation density of $0.16 \mathrm{~km}^{-2}$. Fig. (4) (lithology) shows the statistical result of the relationship between landslides density and lithology. The area underlain by loess and clay has the greatest susceptibility to landslides. The landslides density of this class is $0.3 \mathrm{~km}^{-2}$. Fig. (4) (distance to fault) shows the relationship between landslides
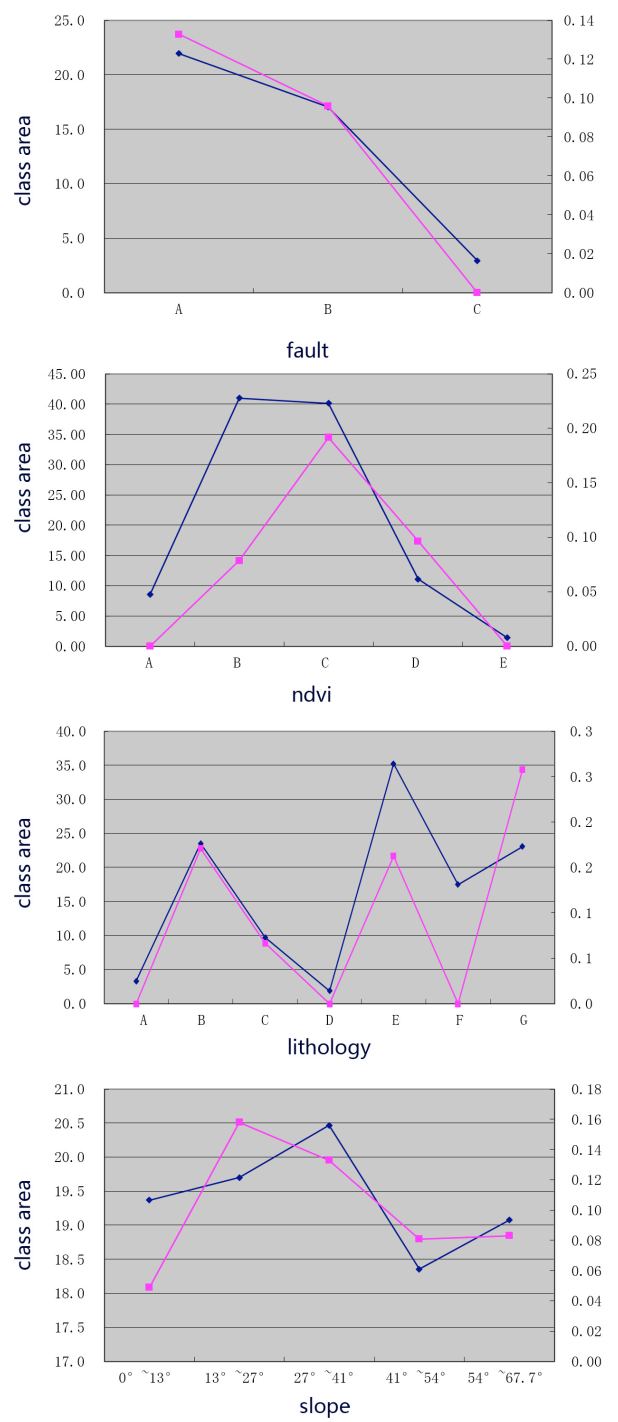

density and distance to fault. As shown in Fig. (3), when the distance becomes longer, the density will become lower. The largest range of distance to fault is in the range of $0 \sim 2.9 \times 10^{6} \mathrm{~m}$, which is $0.13 \mathrm{~km}^{-2}$. Distance to river is similar to distance to fault, as shown in Fig. (4) (distance to river). Landslides easily occur near the river. The largest density of landslides occurred in the range of $0 \sim 9 \mathrm{~m}$, with landslides density of $0.15 \mathrm{~km}^{-2}$. Fig. (4) (land-use) shows correlations between land-use and landslides. Settled area is the largest range in which surface deformation occurred. It indicates that human activity is an important impact factor contributing to landslides susceptibility. The landslides density in this class is $0.27 \mathrm{~km}^{-2}$. Fig. (4) (NDVI) shows that the NDVI ranges of $-0.4 \sim 0$ have the largest landslides density which is $0.19 \mathrm{~km}^{-2}$.

\section{DISCUSSION}

\subsection{Correlation Between Surface Deformation and Landslides}

After getting the spatial distribution of surface deformation and landslides, we compared the distribution of


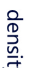

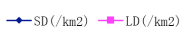

Fig. (5). The correlation between the density of surface deformation and the density of landslides under different impact factors. 
surface deformation and landslides in different impact factors to reveal the correlation between them. Fig. (5) shows the correlation between surface deformation and landslides in different impact factors. Obviously, in lithology, distance to fault, distance to river, land-use and NDVI, the distribution of surface deformation and landslides is almost consistent. It shows that these impact factors have the same impact on surface deformation and landslides. However, in the case of altitude and slope degree, there is different distribution. In the case of altitude, surface deformation is mainly distributed at $835 \mathrm{~m} \sim 1200 \mathrm{~m}$. This distribution is different from landslides, which are mainly distributed at $1200 \mathrm{~m} 2000 \mathrm{~m}$. In the case of slope degree, surface deformation is mainly distributed at $27^{\circ} \sim 41^{\circ}$. This distribution is also different from landslides, which are mainly distributed at $13^{\circ} \sim 27^{\circ}$. It means that altitude and slope degree have different impact on surface deformation and landslides. These different distribution patterns can reveal the distribution features of surface deformation and landslides.

\subsection{Cause of the Different Distributions Between Surface Deformation and Landslides}

In order to study the cause of the different distributions between surface deformation and landslides, we used two classifications: $835 \mathrm{~m} \sim 1200 \mathrm{~m}$ and $1200 \mathrm{~m} \sim 2000 \mathrm{~m}$ in altitude and two classifications: $13^{\circ} \sim 27^{\circ}$ and $27^{\circ} \sim 41^{\circ}$ in slope degree
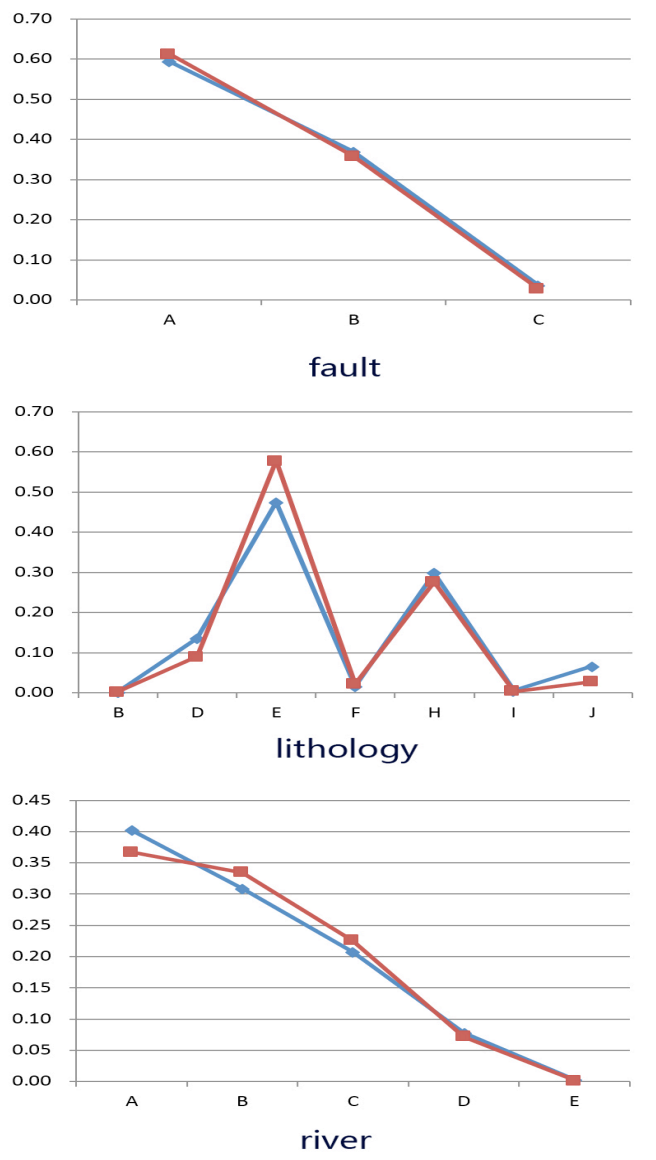

$\longrightarrow 27^{\circ} \sim 41^{\circ}$ for a thorough research. In total, there are seven impact factors. The feature class (such as $835 \mathrm{~m} \sim 1200 \mathrm{~m}$, in altitude) is correlated with other impact factors. Using Area Ratio Index, we calculated the area ratio that the feature classes distribute based on different class under the same impact factors. The possible controlling factors may be revealed in the comparison.

\subsubsection{Slope Degree}

Fig. (6) shows the correlation between two different feature classes in slope degree with impact factors including altitude, lithology, fault, land-use, NDVI and distance to river. The feature class $13^{\circ} \sim 27^{\circ}$ is the main distribution of surface deformation. And the feature class $27^{\circ} \sim 41^{\circ}$ is the main distribution of landslides. In Fig. (6), the blue line shows $13^{\circ} \sim 27^{\circ}$ class, and the red line shows $27^{\circ} \sim 41^{\circ}$ class. As is shown in Fig. (6), the distributions of two feature classes are almost consistent. It indicates that impact factors including altitude, lithology, fault, land-use, NDVI, and distance to river have the same impact on surface deformation and landslides. There is no information of which factors may control surface deformation or landslides.

\subsubsection{Altitude}

Fig. (7) shows the correlation between two different feature classes in altitude with impact factors including slope

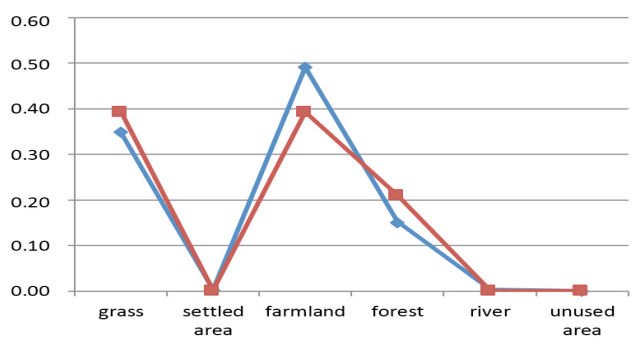

landuse
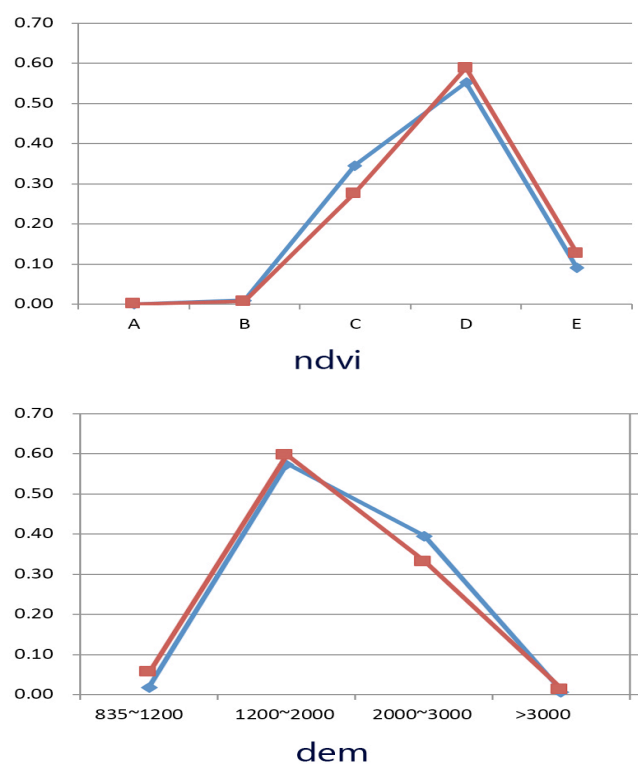

Fig. (6). The correlation between two different feature classes under slope degree. 
degree, lithology, fault, land-use, NDVI, and distance to river. The feature class $835 \mathrm{~m} \sim 1200 \mathrm{~m}$ shows the main distribution of surface deformation. The feature class $1200 \mathrm{~m} \sim 2000 \mathrm{~m}$ shows the main distribution of landslides. In Fig. (7), the blue line is $835 \mathrm{~m} \sim 1200 \mathrm{~m}$ class and the red line is $1200 \mathrm{~m} \sim 2000 \mathrm{~m}$ class. Obviously, the distributions of two feature classes are different in impact factors except the fault. Fig. (7) (fault) shows the similar trend between two feature classes. It indicates that the fault has the same impact on surface deformation and landslides. When the distance becomes nearer to the fault, the more surface deformation or landslides occur.

In Fig. (7) (slope degree), blue line shows that the feature class $835 \mathrm{~m} \sim 1200 \mathrm{~m}$ is mainly distributed on the slope degree ranges of $0^{\circ} \sim 13^{\circ}$. Red line shows that the feature class $1200 \mathrm{~m} \sim 2000 \mathrm{~m}$ is mainly distributed on the slope degree ranges of $13^{\circ} \sim 41^{\circ}$. As already established, the slope degree threshold of landslides is $15^{\circ}$. It is easy to distinguish surface deformation and landslides by the results of SBAS-InSAR points.

In Fig. (7) (lithology), blue line shows that the feature class $835 \mathrm{~m} \sim 1200 \mathrm{~m}$ is underlain by thin-layered siltstone and mudstone. Red line shows that the feature class $1200 \mathrm{~m} \sim 2000 \mathrm{~m}$ is underlain by medium thickness limestone
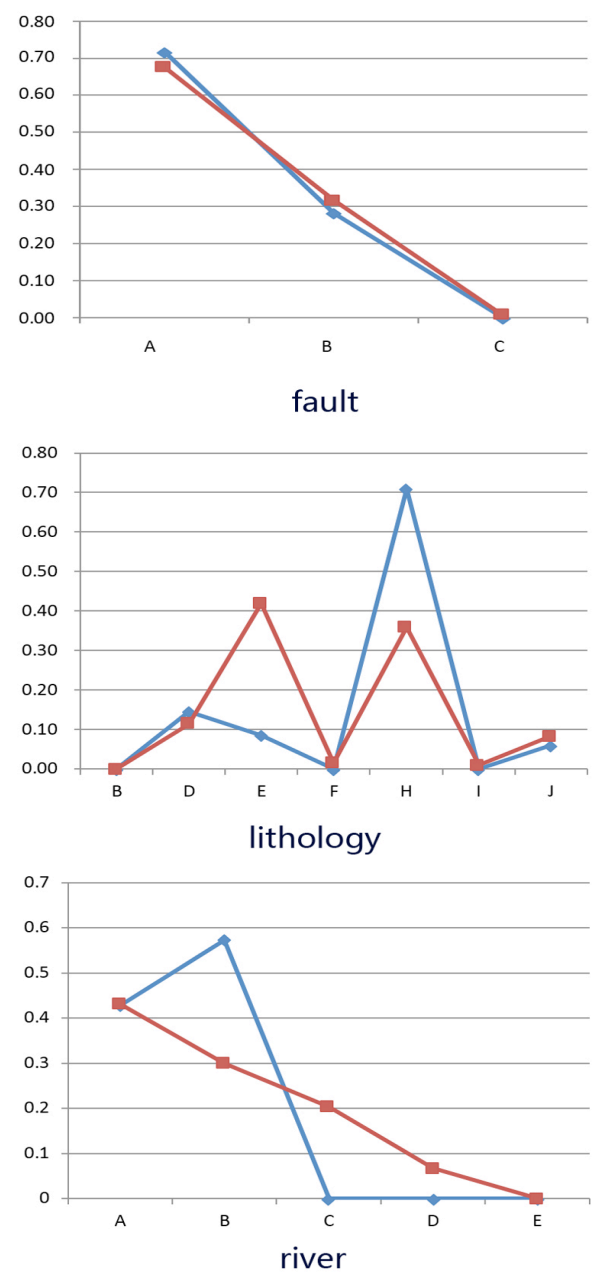

and thin-layered siltstone and mudstone. These materials have been weathered away into loose materials. Thin-layered siltstone and mud stone have strong control on surface deformation and landslides. Different from surface deformation, landslide is also controlled by medium thickness limestone. The distributions of two-type lithology indicates the distribution trend of surface deformation and landslides.

In Fig. (7) (land-use), blue line shows that the feature class ranging between $835 \mathrm{~m} \sim 1200 \mathrm{~m}$ is mainly distributed on the farmland. Red line shows that the feature class ranging between $1200 \mathrm{~m} \sim 2000 \mathrm{~m}$ is mainly distributed both on the farmland and grass. The distribution of landslides (Fig. 4) shows that landslides are mainly distributed on areas such as farmland and settled area which have strong human activity. Human activities aggravate the weathering of rock and may cause the failure of slope.

In Fig. (7) (NDVI), blue line shows that the feature class ranging between $835 \mathrm{~m} \sim 1200 \mathrm{~m}$ is mainly distributed on $0.4 \sim 0$. Red line shows that the feature class ranging between $1200 \mathrm{~m} \sim 2000 \mathrm{~m}$ is mainly distributed on $-0.7 \sim-0.4$. It indicates that landslides are mainly distributed on the poor vegetation covered areas.
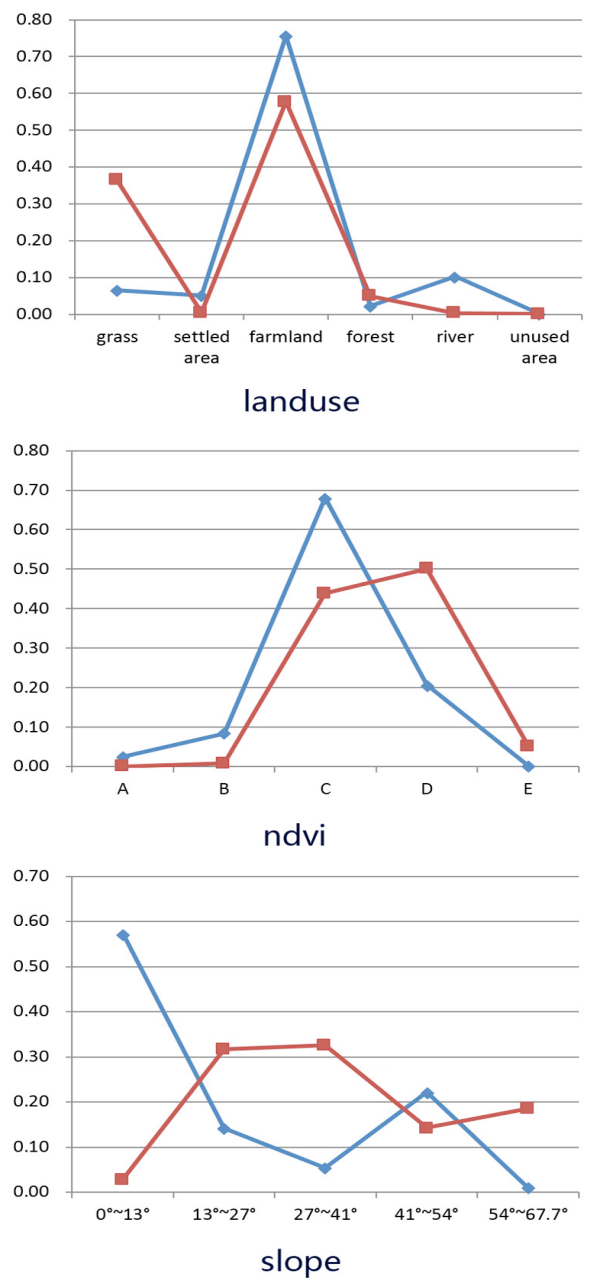

Fig. (7). The correlation between two different feature classes under altitude. 


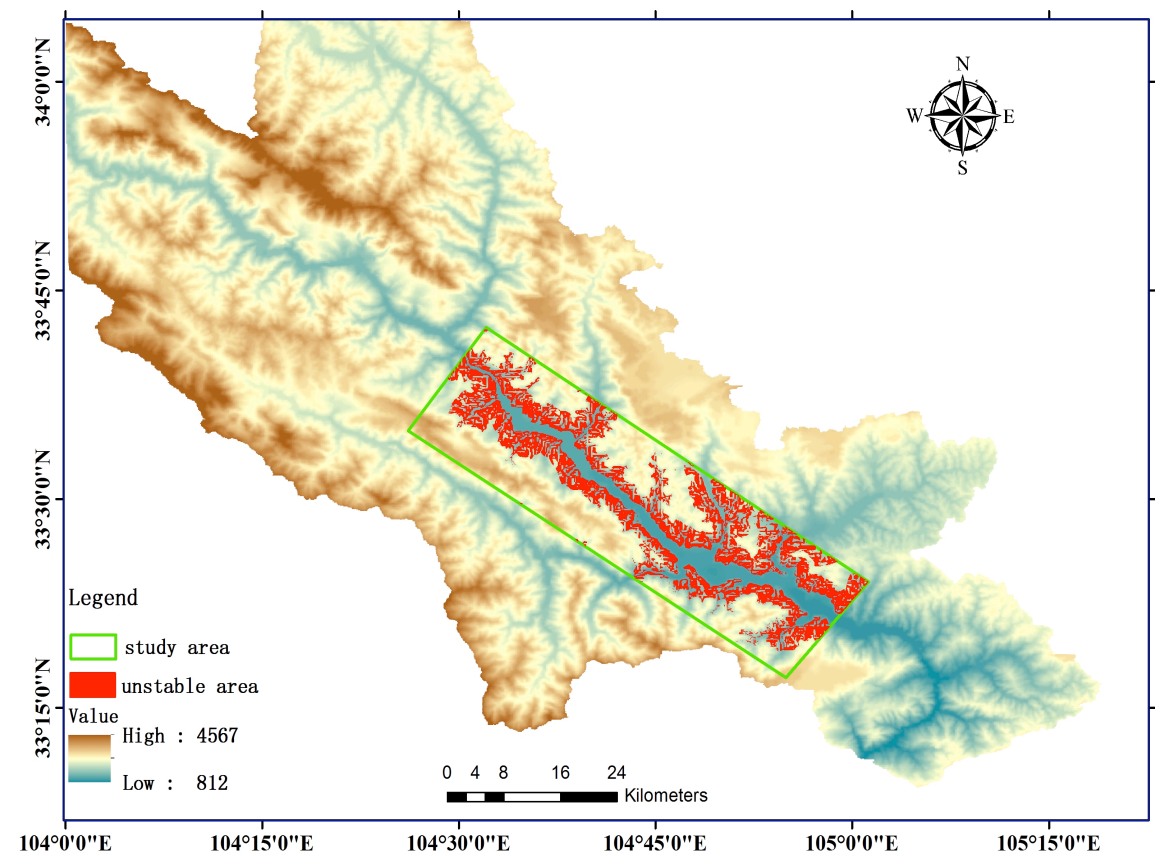

Fig. (8). The unstable area based on landslides susceptibility.

In Fig. (7) (distance to river), blue line shows that the feature class ranging between $835 \mathrm{~m} \sim 1200 \mathrm{~m}$ increases with the distance far away from the river. Red line shows the feature class ranging between $1200 \mathrm{~m} \sim 2000 \mathrm{~m}$ decreases with the distance far away from the river. It indicates that landslides usually occur near the river. In study areas, the river valley is ' $\mathrm{V}$ ' shaped. The river scours the riverbank constantly. It makes slope to form free face which can cause landslides.

\subsection{The Landslide Susceptibility Areas.}

In summary, the study is conducted to find correlation between surface deformation and landslides. Using these relationships, we can easily identify landslides through results of SBAS-InSAR directly. The features of landslides distribution was chosen to map the landslides susceptibility areas. This method can weed out the surface deformation points which are not landslides. Using ArcGIS 10.2, we overlaid the different landslides distribution features which were obtained from the correlation status of surface deformation and landslides. Finally, the landslides susceptibility areas are shown in Fig. (8).

\section{CONCLUSION}

SBAS-InSAR technology is an accurate and swift method to measure surface deformation on a large scale. Using SBAS-InSAR, we got the results of surface deformation on study area. By correlating the surface deformation with impacting factors including the altitude, lithology, slope degree, land-use, fault, NDVI and distance to river, we got the distribution trend of surface deformation. The same work was applied to landslides which we extracted from SPOT 5 image and investigated in the field. After that, the comparison analysis was performed, which reveals that slope degree and altitude have different impact on surface deformation and landslides. Through a rigorous research, we found that the landslides are mainly distributed based on: $13^{\circ} \sim 41^{\circ}$ slope degree; $1200 \mathrm{~m} \sim 2000 \mathrm{~m}$ altitude; the strong human activity; the poor vegetation is covered; near the river and fault; underlain medium thickness limestone and thinlayered siltstone and mudstone. These feature classes can help us to build the model of the landslides distribution. Using the landslides distribution model, landslides will be identified from the results of surface deformation. Landslides susceptibility will be assessed. This method can help local government to rapidly monitor landslides and assess landslides susceptibility on a large scale. Unlike the traditional landslides investigative methods, it can reduce expenses and time.

\section{CONFLICT OF INTEREST}

The authors confirm that this article content has no conflict of interest.

\section{ACKNOWLEDGEMENTS}

This research was supported by the National Key Technology R\&D Program, China (No. 2011BAK12B06), the Science and Technology Key Project of Gansu province, China (No. 1102FKDA007) and International S\&T Cooperation Program of China (ISTCP) (No. 2013DFE23030).

\section{REFERENCES}

[1] J.L. Yue, Research Hazards in Longnan, People of Gansu Publisher, China, 2011, p. 82.

[2] L. Tan, G. Chen, R.Q. Zeng, and X. M. Meng, "Application of artificial neural network in landslide susceptibility assessment", Journal of Lanzhou University (Natural Sciences), vol. 50, pp. 1520, 2014.

[3] X. Su, W. J. Wu, and W. L. Ye, "Characteristics and stability assessment of Longjiongxincun landslide in Zhouqu County, Gansu 
Province", Journal of Lanzhou University (Natural Sciences), vol.50, pp. 7-14, 2014.

[4] M. Ao, C. C. Wang, and R. A. Xie, "Monitoring the land subsidence with persistent scatterer interferometry in Nansha District, Guangdong, China", Natural Hazards, 2014. DOI: 10.1007/s11069-014-1471-2.

[5] J. Z. Zhang, H. J. Huang, and H. B. Bi, "Land subsidence in the modern Yellow River Delta based on InSAR time series analysis", Natural Hazards, 2014. DOI: 10.1007/s11069-014-1434-7.

[6] B. B. Chen, H. L. Gong, X. J. Li, K. C. Lei, Y. H. Ke, G. Y. Duan, and C. F. Zhou, "Spatial correlation between land subsidence and urbanization in Beijing, China", Natural Hazards, 2014, DOI: 10.1007/s11069-014-1451-6.

[7] Y. Huang, Y. J. Bao, and Y. H. Wang, "Analysis of geoenvironmental hazards in urban underground space development in Shanghai", Natural Hazards, 2014, DOI: 10.1007/s11069-014-1414-y.

[8] J. Hu, Q. J. Wang, Z. W. Li, R. A. Xie, X. Q. Zhang, and Q. Sun, "Retrieving three-dimensional coseismic displacements of the 2008 Gaize, Tibet earthquake from multi-path interferometric phase analysis", Natural Hazards, vol. 73, pp. 1311-1322, 2014.

[9] C. Colesanti, and J. Wasowski, "Investigating landslides with space-borne Synthetic Aperture Radar (SAR) interferometry", Engineering Geology, vol. 88, pp. 173-199, 2006.
[10] A. Ferretti, C. Prati, and F. Rocca, "Nonlinear subsidence rate estimation using Permanent Scatterers in differential SAR interferometry", IEEE Transactions on Geoscience and Remote Sensing, vol. 38, no. 5, pp. 2002-2012, 2000.

[11] A. Hooper, H. Zebker, P. Segall, and B. Kampes, "A new method for measuring deformation on volcanoes and other natural terrains using InSAR persistent scatterers", Geophysical Research Letters, vol. 31, no. 23, pp. 611-615, 2004.

[12] S. C. Oliveira, J. L. Zezere, J. Catalao, and G. Nico, "The contribution of PSInSAR interferometry to landslide hazard in weak rock- dominated areas", Landslides, 2014, DOI 10.1007/s10346-014-0522-9.

[13] C. Xu, X. W. Xu, J. B. H. Shyu, W. J. Zheng, and W. Min, "Landslides triggered by the 22 July 2013 Minxian-Zhangxian, China, Mw 5.9 earthquake: Inventory compiling and spatial distribution analysis", Journal of Asian Earth Sciences, vol. 92, pp. 125-142, 2014

[14] P. Berardino, G. Fornaro, R. Lanari, and E. Sansosti, "A new algorithm for surface deformation monitoring based on small baseline differential SAR interferometry", IEEE Aerospace and Electronic Systems Magazine, vol. 40, no. 11, pp. 2375-2383, 2002.

[15] A. Hooper, and H. Zebker, "Phase unwrapping in three dimensions with application to InSAR time series", Optical Society of America, vol. 24, no. 9, pp. 2737-2747, 2007.

(C) Yating et al.; Licensee Bentham Open.

This is an open access article licensed under the terms of the (https://creativecommons.org/licenses/by/4.0/legalcode), which permits unrestricted, noncommercial use, distribution and reproduction in any medium, provided the work is properly cited. 